\title{
The Development of Augmented Reality Application to Explore Fluid Concepts
}

\author{
Handjoko Permana ${ }^{1, a)}$, Fauzi Bakri ${ }^{1}$, Indah Hanifa Salsabila ${ }^{1}$, \\ Diah Ambarwulan ${ }^{1}$, Dewi Muliyati ${ }^{1}$, Dadan Sumardani ${ }^{2, b)}$ \\ 'Physics Education Study Program, Faculty of Mathematics and Natural Sciences, Universitas \\ Negeri Jakarta, Jakarta, 13220, Indonesia. \\ ${ }^{2}$ Teachers College, National Chiayi University, Chiayi, 300, Taiwan

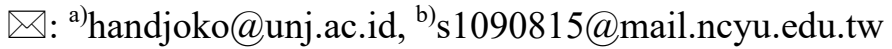

\begin{abstract}
Exploration can be done by reading, discussing, or experimenting with collecting and processing data. In fluid material, students can explore by looking at the phenomena related to the application of Archimedes' law, Pascal's law, and Bernoulli's law. This study aims to develop teaching materials that can improve students' ability to explore fluid material. The research method used is the 4D model development research. The study results were in marker applications and augmented reality, which was validated by material experts, learning media. This application has also gone through field trials. The validation value of material experts is $86 \%$, and media experts are $82.5 \%$. Meanwhile, the test results for the teacher obtained $83.75 \%$, and the students obtained $83.45 \%$. Based on the validation results, this media is feasible to be used as a learning medium that helps students improve fluid material.
\end{abstract}

Keywords: application, augmented reality, development, exploring, fluid

\section{INTRODUCTION}

Exploration is included in the analysis section (C4) at the cognitive level (Anderson and Krathwohl 2001). Also, the analysis section (C4) is included in activities that train High Order Thinking Skills (HOTS) (Pratama and Retnawati 2018). HOTS is difficult to define but easily recognized when encountered (Resnick 1992). Thomas and Thorne stated that higher-order thinking is thinking at a higher level than merely remembering facts or retelling something that other people have heard (Thomas and Thorne 2009). Thomas and Thorne said that higher-order thinking requires one to do something about facts, namely understand them, summarize them, relate them to points in new ways and apply them to find solutions to problems (Thomas and Thorne 2009). Higher-order thinking occurs when students acquire new knowledge and store it in memory (Abosalem 2016). Then this knowledge is correlated with previous experience to achieve individual goals (Abosalem 2016). In other words, HOTS occur when someone gets new information, understands it, and associates it with existing knowledge, and then passes that information on to achieve a specific object or solution to a problem (Hassan, Rosli and Zakaria 2016). High-level thinking associated with the process includes conceptual understanding, systematic review, problem-solving, and critical thinking (Brookhart and Nitko 2011). This process is formed on an ongoing basis, ultimately to reach HOTS in individuals. Therefore, HOTS must be trained towards learners (Abdullah et al. 2016). Thus, teachers can introduce HOTS to students using the right media, methods, and learning approaches (Budsankom, Sawangboon, Damrongpanit and Chuensirimongkol 2015) (Agustihana and Suparno 2018). 
Exploring is a learning stage in which students are asked to actively study and seek or find information on new knowledge/concepts, new techniques, new methods, and formulas, or investigate patterns of relationships between elements of science concepts while trying to understand them (Robert 1985). The manifestation of exploration activities in the classroom, including study the material in textbooks by reading comprehension, make practicum/demonstration/conduct field trials or laboratories observe objects and natural phenomena (e.g, plants, body anatomy, water infiltration on paper), and record observations as reports (Robert 1985).

There are many things in the topic of learning physics that can be explored, such as fluids. The fluid is a collection of molecules regulated by forces (cohesion and adhesion) and by forces acting by the walls of the container (Sulasih, Suparmi and Sarwanto 2017). Liquids and gases are classified as fluids. In studying static fluids, we do not need to learn new physical principles to explain the pressure and buoyancy acting on floating and sinking bodies (Loverude, Kautz and Heron 2003). The behavior of floating and immersed objects in static fluids can be explained using Newton's laws (Parno, Yuliati, Ndadari and Ali 2020).

Meanwhile, dynamic fluid is one of the physics concepts studied in various disciplines (Martin, Mitchell and Newell 2003) at different education levels, one of which is at the high school level. High school students learn at least some of the sub-content in the dynamic fluid concept, namely features of the ideal fluid, discharge, continuity equations, Bernoulli's principle, and Torricelli's theory. Dynamic fluid can be defined as a moving fluid (Cutnell and Johnson 2011) and is a concept that is learned after the static fluid. Some concepts in dynamic fluids are related to static fluids, such as pressure, hydrostatic pressure, etc., so that to explain a phenomenon related to fluid dynamics, students must also understand the concept of static fluid (Dewi, Samsudin and Nugraha 2019). Therefore, trying to understand this concept runs into different complexities and difficulties.

Currently, there is also Augmented Reality (AR) technology. AR technology is increasingly becoming a trend in many fields. Initially, in the tourism sector, AR technology can be a unique and exciting entertainment medium (Permana, Muliyati, Bakri, Dewi and Ambarwulan 2019). Furthermore, in gaming, AR technology causes many users to waste time using smartphones as devices to play with AR technology. This development makes AR technology one of the current development trends in education: AR technology offers a more realistic and unique learning environment related to interactions with users (FitzGerald et al. 2013). So, it is not surprising that the student can use this technology as a tool that can help students explore.

AR as a medium for exploration in physics studies has been carried out on the topic of magnets by Buesing and Cook (2013) and Bakri, Sumardani and Muliyati (2019), about density conducted by Craciun and Bunoiu (2017), on hot topics carried out by Bakri, Pratiwi and Muliyati (2019). On the magnets developed by Buesing and Cook (2013), students were asked to observe the phenomenon of lines of magnetic force and describe it. After being tested, it turned out that students who used the AR apps had significant drawing compared to classes that only used books (Buesing and Cook 2013). But the group that used books scored better on tests. Meanwhile, AR for the topic of magnetism developed by Bakri, Sumardani and Muliyati (2019) displays a 3D animation that shows an illustration of Lorentz force in many variations (Bakri, Sumardani and Muliyati 2019). On the Density topic developed by Craciun and Bunoiu (2017), students were given animation of density from regular and irregular bodies with various circumstances then students were asked to determine the density value (Crăciun and Bunoiu 2017). On the hot topic developed by Bakri, Pratiwi and Muliyati (2019), students conducted exploration activities by observing videos about black principles (Bakri, Pratiwi and Muliyati, Videoenriched worksheet based on augmented reality technology: The heat experiment is easier 2019). Therefore, in this research, augmented reality will be developed to explore fluid material. AR will be displayed in the form of animation, simulation, and video.

\section{METHODS}

This AR application develops to explain fluid phenomena, both static fluid, and dynamic fluid. The development research model used is the Four-D model (Thiagarajan, Semmel and Semmel 1974), but only includes defining, designing, and developing stages, not to the disseminate stage. The 
validation of material media experts, learning, and field trials at the development stage. The following is an explanation of the three steps:

\section{Define}

At this stage, a literature study is to assess the basic competencies of class XI. The basic competencies that are studied are 3.3 Applying the laws of static fluids in everyday life and 3.4 Applying the principles of dynamic fluids in technology. The study results are a list of fluid topics to be made AR, both in video and animation.

\section{Design}

The design stage making a marker and designing the AR to be displayed. Markers create must match the AR to be displayed. In making AR videos, researchers make a storyline in advance so that it is easy to make the video. The video's storyline includes an opening, a core, and a closing.

\section{Develop}

The development stage aims to produce AR products that are following the Design stage. Developing AR is done using Unity software. Also, an assessment of instructional media experts, material experts, and field tests on teachers and students. Evaluation of instructional media experts is carried out by asking 11 items of questions, split into two aspects. Evaluation by material experts by giving questions as many as 31 items divided into three parts. Assessment by the teacher as users as 25 questions which divided into four parts and by the student users as 11 questions which divided into two parts. The rating scale ranges from one to five, with one strongly disagreeing, two strongly disagreeing, three hesitating, four agreeing, and five strongly agreeing.

\section{RESULTS AND DISCUSSION}

As with other AR applications, to bring up AR, the user must point the application's camera at the marker. The results of the development are presented in TABLE 1 . TABLE 1 contains the material, the marker image used to generate $\mathrm{AR}$, and the $3 \mathrm{D}$ animation design or video products that will be displayed. This marker image can be printed on paper or in a soft copy.

TABLE 1. The results of the development

\begin{tabular}{lll}
\multicolumn{1}{c}{ Matters } & Marker & AR Design \\
\hline Static fluid \\
Archimedes' law
\end{tabular}




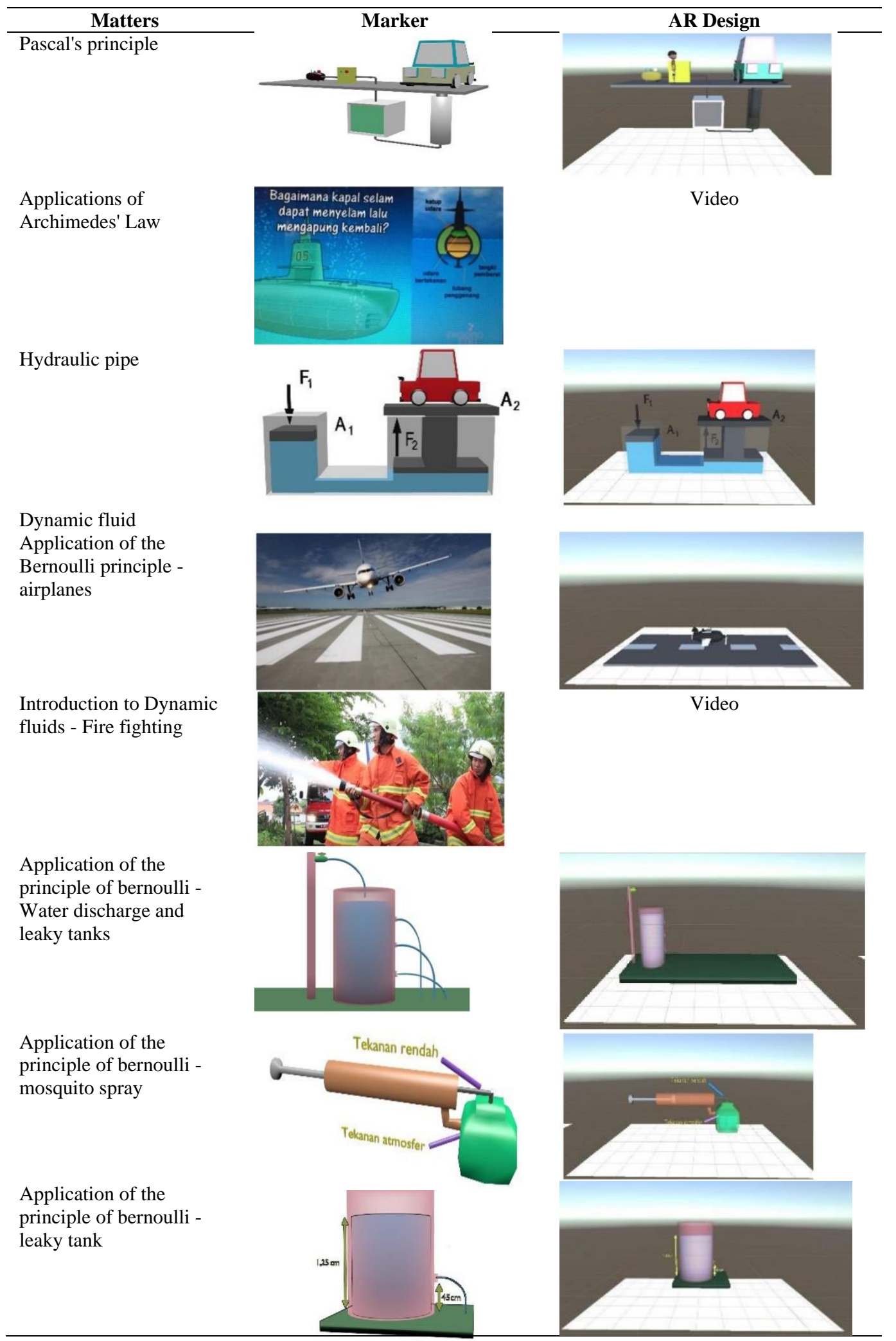

There were ten markers made in total. The static fluid material produced five markers. one marker for displaying video and four markers for displaying 3D animation. Video made on the material applying Archimedes' law to submarines. Four 3D animations develop on Pascal's law and Archimedes' law. Meanwhile, five markers were produced in a dynamic fluid material. One of marker for displaying video and four markers for displaying 3D animation. 3D animation and video made to explain the law of Bernoulli. 
The AR was validated by material, media, and field-testing experts by students and teachers. The results of expert validation and field testing presented in TABLE 2. Based on the data in TABLE 2, the results of the validation of media experts, material experts, and teacher and student field tests show that the AR media developed is very suitable for use as a medium for exploration.

TABLE 2. Validation result and field testing

\begin{tabular}{|c|c|c|c|}
\hline No & $\begin{array}{r}\text { Aspect } \\
\end{array}$ & Percentage & Interpretation \\
\hline \multicolumn{4}{|c|}{ Validation to Media expert } \\
\hline 1 & AR Interface & $80.0 \%$ & Feasible \\
\hline 2 & $\mathrm{AR}$ media function & $85.0 \%$ & Very feasible \\
\hline & Average & $82.5 \%$ & Very feasible \\
\hline \multicolumn{4}{|c|}{ Validation to Material expert } \\
\hline 1 & Material suitability & $86.0 \%$ & Very feasible \\
\hline 2 & Presentation & $88.0 \%$ & Very feasible \\
\hline 3 & The language & $84.0 \%$ & Very feasible \\
\hline & Average & $86.0 \%$ & Very feasible \\
\hline \multicolumn{4}{|c|}{ Field Test to Teacher } \\
\hline 1 & The material suitability & $82.7 \%$ & Very feasible \\
\hline 2 & The consistency of the material & $80.0 \%$ & Feasible \\
\hline 3 & The language & $83.3 \%$ & Very feasible \\
\hline 4 & AR media & $89.0 \%$ & Very feasible \\
\hline & Average & $83.75 \%$ & Very feasible \\
\hline \multicolumn{4}{|c|}{ Field Test to Students } \\
\hline 1 & Augmented Reality & $83.45 \%$ & Very feasible \\
\hline 2 & Usefulness & $83.45 \%$ & Very feasible \\
\hline & Average & $83.45 \%$ & Very feasible \\
\hline
\end{tabular}

After exploring the static fluid material, students are expected to be able to; 1 . Describe the concept of hydrostatic pressure; 2. Use the principle of Pascal's Law to calculate physical quantities on hydraulic equipment; and 3. Use Archimedes' Law principles to solve physical cases related to objects that sink, float, and float in substances liquid. Meanwhile, after exploring dynamic fluid material, students are expected to use the Bernoulli Principle. Students can formulate the Bernoulli Principle to determine the velocity of the liquid emission through the tank leakage, the speed of fluid flow (liquid) through the venturi meter, the speed of flow through the pitot tube, and the magnitude of the plane.

The result of media experts, the percentage for the AR interface gets $80 \%$. It is a small value compared to the AR function because the AR application's menu display is less attractive. In the expert assessment of the percentage of language gets $84 \%$. It is a small percentage from other aspects because the written of the AR application menu can still be made shorter. In the field tests, according to the teacher, the material's consistency gets $80 \%$. It was the least because the number of AR displayed for each material should be the same. Field tests with both aspects of students get the same percentage, $83.45 \%$.

Exploration activities using AR is considered more effective. The marker scan time of two seconds shows that AR is more effective and efficient than student searching and downloading animation or videos (Bakri, Marsal and Muliyati, Textbooks Equipped with Augmented Reality Technology for Physics Topic in High-School 2019). The use of AR, of course, uses a smartphone or mobile-based and work offline, so it does not need an internet (Bakri, Sumardani and Muliyati 2019). In the research conducted by (Eveline, Suparno, Ardiyati and Dasilva 2019) using mobile-based applications, it was found to be effective in increasing student HOTS. The learning process assisted by mobile media can help students complete HOTS aspects and improve students' 21st-century skills (Eveline, Suparno, Ardiyati and Dasilva 2019).

From the Sulasih, Suparmi and Sarwanto (2017), most of the static fluids that are difficult to understand are Archimedes' Law. The students' difficulties occurred in understanding the phenomenon of floating, fully submerged, and drowning objects. That is why in the chapter on static fluid, in addition to making 3D animations on the law of Archimedes, researchers also made AR videos to explain the concept of floating, fully submerged, and submerged objects in a submarine.

Meanwhile, Dewi, Samsudin and Nugraha (2019) research show that the difficulty in studying dynamic fluids occurs in applying Bernoulli's law. Based on students' answers, the problem occurs because students cannot explain the relationship between pressure and speed. Also, students have 
misconceptions about the relationship between pressure and velocity at different cross-sectional areas. That is why researchers have created many $3 \mathrm{~d}$ animations related to Bernoulli's law applications. In this chapter, four ARs explain the law application of Bernoulli from a total of five ARs.

\section{CONCLUSION}

This research has produced Augmented Reality to assist students in exploring fluid material. In this development, the fluid material developed consists of static and dynamic fluid material. Each material developed has five AR, which is a combination of 3D animation and video. Material experts have validated this AR with $86 \%$ and media experts' value with $82.5 \%$. Meanwhile, the teacher's field test results got $83.75 \%$ and got $83.45 \%$ of the students. These results indicate that the AR developed is very suitable to be used as a teaching medium that helps students in explanatory activities.

\section{REFERENCES}

Abdullah, AH, Mokhtar, M, Halim, ND, Ali, DF, Tahir, LM \& Kohar, UH 2016, 'Mathematics teachers, level of knowledge and practice on the implementation of higher-order thinking skills (HOTS)', Eurasia Journal of Mathematics, Science and Technology Education, vol. 13, no. 1, pp. 3-17, doi:10.12973/eurasia.2017.00601a.

Abosalem, Y 2016, 'Assessment Techniques and Students', Higher-Order Thinking Skills, International Journal of Secondary Education, vol. 4, no. 1, pp. 1-12, doi:10.11648/j.ijsedu.20160401.11.

Agustihana, S \& Suparno 2018, 'Effectiveness of Physics Mobile Learning Media to Improve Higher Order Thinking Skills of Students in Thermodynamics', Journal of Physics: Conference Series, vol. 1097, no. 1, p. 012031, doi:10.1088/1742-6596/1097/1/012031.

Anderson, L \& Krathwohl, D 2001, 'A Taxonomy for Learning, Teaching, and Asessing: A Revision of Bloom's Taxonomy of Education Objective', New York: Addison Wesley Lonman Inc.

Bakri, F, Marsal, O \& Muliyati, D 2019, 'Textbooks Equipped with Augmented Reality Technology for Physics Topic in High-School', Jurnal Penelitian and Pengembangan Pendidikan Fisika, vol. 5, no. 2, pp. 113-22.

Bakri, F, Pratiwi, S \& Muliyati, D 2019, 'Video-enriched worksheet based on augmented reality technology: The heat experiment is easier', AIP Conference Proceedings, vol. 2169, no. 1, p. 020010.

Bakri, F, Sumardani, D \& Muliyati, D 2019, 'The 3D simulation of Lorentz Force based on augmented reality technology', Journal of Physics: Conference Series, vol. 1402, no. 6, p. 066038.

Brookhart, M \& Nitko, AJ 2011, 'Assessment and grading in classrooms', New Jersey: Pearson Education Inc.

Budsankom, P, Sawangboon, T, Damrongpanit, S \& Chuensirimongkol, J 2015, 'Factors affecting higher order thinking skills of students: A meta-analytic structural equation modeling study', Educational Research and Review, vol. 10, no. 19, pp. 2639-652, doi:10.5897/ERR2015.2371

Buesing, M \& Cook, M 2013, 'Augmented Reality Comes to Physics', The Physics Teacher, vol. 51, no. 4, pp. 226-28, doi:10.1119/1.4795365

Crăciun, D \& Bunoiu, M 2017, 'Boosting Physics Education through Mobile Augmented Reality', AIP Conference Proceedings, vol. 1916, no. 1, p. 050003.

Cutnell, JD \& Johnson, KW 2011, 'Introduction to physics 9th Edition', New Jersey: Wiley.

Dewi, FH, Samsudin, A \& Nugraha, MG 2019, ‘An investigation of students, conceptual understanding levels on fluid dynamics using four-tier test', Journal of Physics: Conference Series, vol. 1280, no. 5, p. 052037. 
Eveline, E, Suparno, S, Ardiyati, TK \& Dasilva, BE 2019, 'Development of Interactive Physics Mobile Learning Media for Enhancing Students', HOTS in Impulse and Momentum with Scaffolding Learning Approach, Jurnal Penelitian and Pengembangan Pendidikan Fisika, vol. 5, no. 2, pp. 12332.

FitzGerald, E, Ferguson, R, Adams, A, Gaved, M, Mor, Y \& Thomas, R 2013, 'Augmented reality and mobile learning: the state of the art', International Journal of Mobile and Blended Learning, vol. 5, no. 4, pp. 43-58, doi:10.4018/ijmbl.2013100103.

Hassan, SR, Rosli, R \& Zakaria, E 2016, 'The Use of I-Think Map and Questioning to Promote HigherOrder Thinking Skills in Mathematics', Creative Education, vol. 7, no. 7, pp. 1069-1078, doi:10.4236/ce.2016.77111.

Loverude, ME, Kautz, CH \& Heron, PR 2003, 'Helping students develop an understanding of Archimedes, principle. I. Research on student understanding', American Journal of Physics, vol. 71, no. 11, doi:10.1119/1.1607335.

Martin, J, Mitchell, J \& Newell, T 2003, 'Development of A Concept Inventory for Fluid Mechanics', IEEE Frontiers in Education Conference, pp. 23-8.

Parno, Yuliati, L, Ndadari, IP \& Ali, M 2020, 'Project Based Learning Integrated STEM to Increase Students, Scientific Literacy of Fluid Statics Topic', IOP Conf. Series: Journal of Physics: Conf. Series, vol. 1491, no. 1, p. 012030, doi:10.1088/1742-6596/1491/1/012030.

Permana, AH, Muliyati, D, Bakri, F, Dewi, BP \& Ambarwulan, D 2019, 'The development of an electricity book based on augmented reality technologies', IOP Conf. Series: Journal of Physics: Conf. Series , vol. 1157, no. 3, p. 032027.

Pratama, GS \& Retnawati, H 2018, 'Urgency of Higher Order Thinking Skills (HOTS) Content Analysis in Mathematics Textbook', IOP Conf. Series: Journal of Physics: Conf. Series, vol. 1097, p. 012147, doi:10.1088/1742-6596/1097/1/012147.

Resnick, LB 1992, 'Educational and Learning to Think', Washington DC: National Academy Press.

Robert, JM 1985, 'Learning by Exploration', IFAC Proceedings, vol. 18, no. 10, pp. 189-93, doi:10.1016/S1474-6670(17)60218-0.

Sulasih, Suparmi, A \& Sarwanto 2017, 'Profile of student critical thinking ability on static fluid concept', IOP Conf. Series: Journal of Physics: Conf. Series, vol. 909, no. 1, p. 012060.

Thiagarajan, S, Semmel, DS \& Semmel, MI 1974, 'Instructional development for training teachers of exceptional children: A sourcebook', Bloomington: Indiana University.

Thomas, A \& Thorne, G 2009, 'How To Increase Higher Order Thinking', Los Angeles: Center for Development and Learning. 
